\title{
Invasive and non-invasive fractional flow reserve index in validation of hemodynamic severity of intracoronary lesions
}

\author{
Jarosław Wasilewski ${ }^{1}$, Kryspin Mirota², Michał Hawranek ${ }^{1}$, Lech Poloński ${ }^{1}$ \\ 13rd Department of Cardiology, Silesian Center for Heart Diseases, Medical University of Silesia, Zabrze, Poland \\ 2University of Bielsko-Biala, Poland
}

Postep Kardiol Inter 2013; 9, 2 (32): 160-169

DOI: $10.5114 /$ pwki.2013.35452

\begin{abstract}
This review discusses visual and functional evaluation of the hemodynamic significance of the degree of stenosis in coronary angiography, with respect to the indications for revascularization. The concept of the coronary flow reserve is defined, and the theoretical assumptions of the invasive measurement of the fractional flow reserve (FFR) are presented. In the following part, the publication describes the basic steps of numerical stimulations in terms of computational fluid dynamics (CFD) in calculating the fractional flow reserve based on computed tomography $(C T)$ coronary angiography $\left(F F R_{C T}\right)$. The numerical $F F R_{C T}$ estimation in correlation with invasive measurements, as well as benefits deriving from $\mathrm{FFR}_{\mathrm{CT}}$ in the diagnosis of coronary artery disease, is presented in the example of the multicentre prospective DISCOVER-FLOW trial and the DeFACTO project. The CDF method enables to obtain hemodynamic significance of stenosis solely from the coronary anatomy vizualized by CT angiography. The calculation of FFR $\mathrm{CT}_{\mathrm{CT}}$ increases the diagnostic reliability of coronary flow reserve estimations. It contributes to the improvement in patients' qualification for contrast coronarography. If the accuracy of $F F R_{C T}$ is confirmed in clinical practice, and the time required for computational processing is shortened, it may turn out that the algorithms of coronary heart disease diagnosis will be verified and it will be to a greater extent based on the CT results.
\end{abstract}

Key words: fractional flow reserve, computational fluid dynamics.

\section{Problems with assessment of the hemodynamic significance of atherosclerotic lesions}

Coronary angiography remains the "gold standard" of assessment of atherosclerotic lesions. However, this study has some limits. One of them is visualization of the opacification of vessel lumen only without any information about the vessel wall. Besides, depiction of the three-dimensional course of the vessel in two dimensions makes eccentric plaques appear as lesions of variable degrees of stenosis in various projections. Visual assessment is not reliable not only because of its subjective nature, but also because of the fact that the degree of stenosis varies in successive projections. An additional obstacle consists of overlaping coronary artery contours, which may require customized projections. Another source of errors consists of inhomogeneous distribution of contrast agent, particularly at sites of arterial bifurcations, which are particularly prone to the development of atherosclerotic plaques. Even if a particular stenosis can be adequately assessed by the coronarography, it is still impossible to estimate whether the atherosclerotic plaque really limits coronary reserve [1-7]. The degree of stenosis does not necessarily express the functional significance of the lesion [8]. As demonstrated by the analysis of the subgroup of patients from the COURAGE trial (Clinical Outcomes Utilizing Revascularization and Aggressive Drug Evaluation), in approximately $40 \%$ of subjects with significant stenosis visible on coronary angiography there is no inducible ischemia or there are only small perfusion deficits on SPECT (Single Photon Emission Computed Tomography) [9]. It is believed that the greater the degree of stenosis the greater the likelihood that the lesion is hemodynamically significant. It is generally true and it is as-

\section{Corresponding author:}

Jarosław Piotr Wasilewski MD, PhD, 3rd Department of Cardiology, Silesian Center for Heart Diseases, 9 Marii Skłodowskiej-Curie St, 41-800 Zabrze, Poland, tel.: +48 3227152 61, e-mail: jaroslaw-wasilewski@wp.pl

Received: 25.12.2012, accepted: 22.04.2013. 
sumed that stenosis of more than $70 \%$ is functionally significant. In fact, some of these lesions do not limit the coronary reserve. Revascularization of non-significant lesions does not bring clinical benefits and generates costs not only for the healthcare system, but also for the patient. The use of drug-eluting stents, for example, creates the need for a few months of antiplatelet therapy $[3,5]$. Particular controversies are related to revascularization of intermediate lesions (with reduction of the vessel diameter between $50 \%$ and $70 \%$ ). It has been estimated that around half of them are hemodynamically significant, but they are sometimes disregarded during revascularization $[5,8,10]$. Rarely, in approximately $10 \%$ of cases, even stenosis between $40 \%$ and $50 \%$ may cause a decrease of coronary reserve [10]. In the case of borderline lesions visual assessment and even quantitative angiography or intravascular ultrasound (IVUS), which additionally shows the vessel wall, do not permit one to differentiate lesions which require intervention from those which may be treated conservatively [11]. Its usefulness is limited to the description of plaque morphology and degree of stenosis. Whether the lesion is responsible for exertional limitation of blood flow also depends on factors other than the degree of stenosis itself. These include: the length and shape of the plaque, its location (on the curve, on the bifurcation), the presence of other lesions, the status of collateral circulation, the rheological properties of the blood and mostly the amount of viable myocardium supplied by the stenosed artery. If the artery supplies a large area of myocardium, a larger increase of blood flow should be expected during pharmacologically provoked hyperemia, which should translate into a higher gradient of pressure loss across the lesion. This means that if lesions with a similar degree of stenosis are located in the proximal part of the anterior descending artery and in the diagonal branch, the first one will have a higher clinical significance [12]. To justify the necessity of revascularization it is necessary to document that the stenosis limits the flow under conditions of increased oxygen demand. It is believed that prognosis improves only after revascularization aimed at removal of ischemia [9]. The annual risk that a functionally insignificant plaque will cause death or myocardial infarction is low - approximately 1\% [13]. In that situation an intervention on coronary arteries does not improve the prognosis and puts a patient at risk of early and long-term complications related to the intervention $[3,13,14]$. On the other hand, if a patient with a functionally significant stenosis and inducible ischemia is treated conservatively, the annual risk of cardiovascular events is between $5 \%$ and $10 \%$ [15]. For these reasons qualification for revascularization should be preceded by examinations assessing coronary reserve. Even if these studies confirm the exertional or pharmacologically provoked ischemia, they often fail to detect a particular ischemia-related lesion $[16,17]$. These examinations are characterized by good sensitivity and specificity in detection of reversible ischemia per se, but often do not permit one to identify a particular artery or a particular lesion. That is a problem especially in relation to multilevel or diffused lesions. One of the methods used to assess hemodynamically significant stenosis is the measurement of fractional flow reserve during coronary angiography. The diagnostic accuracy of fractional flow reserve (FFR) $\leq 0.8$ to detect ischemia on stress testing is $90 \%$ and FFR $>0.8$ practically excludes ischemia [18-20]. There is a good correlation between the FFR measurement and hemodynamic significance of the lesion. A detailed analysis of the subgroup of patients from the COURAGE trial showed that FFR measurement in subjects with multi-vessel coronary artery disease reduced the percentage of three-vessel coronary artery disease detection from $27 \%$ to $9 \%$ and two-vessel disease from $43 \%$ to $17 \%$. This has an important significance for decision making on treatment modality [21]. Exclusion of insignificant lesions makes revascularization less aggressive and some patients initially qualified after coronary angiography for coronary artery bypass grafting may be treated with angioplasty following verification by means of FFR or some lesions qualified for percutaneous intervention may be treated with optimal medical therapy. The DEFER study (FFR to Determine the Appropriateness of Angioplasty in Moderate Coronary Stenose) regarding single-vessel coronary artery disease $[13,22]$ and the FAME study (FFR versus Angiography for Multi-vessel Evaluation) [3] in patients with many lesions, the strategy of coronary angioplasty or bypass grafting based on the FFR showed an advantage over revascularization of all lesions qualified as significant on visual assessment. Deferring of percutaneous revascularization $[3,13]$ or coronary artery bypass grafting [2] in patients with FFR value above 0.8 is safe and long-term consequences of such decision are very good [23-27].

Another project, the FAME2 study, was dedicated to assess to what extent percutaneous coronary intervention combined with optimal medical therapy shows an advantage over optimal medical therapy alone in patients with significant lesions determined by FFR. Recruitment to the study was prematurely terminated after randomization of 888 patients with significant stenosis on FFR. The reason for that were significant differences between the study groups in terms of the percentage of patients who required emergency revascularization in the group of patients treated with angioplasty [28]. The results of that study opened a discussion on the issue that studies comparing the efficacy of revascularization, in spite of optimal medical therapy, did not demonstrate the superiority of coronary intervention over conservative treatment, when the decision about revascularization was based solely on the morphological assessment of degree of stenosis on coronary angiography [29-32]. The assessment of functional significance of the lesion is particularly important when revascularization of the left main stem is decided [1, 25, 27, 33]. In that case a significant reduction of the vessel lumen diameter is considered as $50 \%$. Reliable assessment of the left 
main stenosis is crucial as surgical revascularization of insignificant stenosis is related to high risk of functional closure of the bypass made of the internal mammary artery or degeneration of venous bypasses or bypasses made of the radial artery [34]. Competitive flow in the native artery decreases shear stress in the bypasses, which leads to their atherosclerotic injury and functional closure [35-37]. The prognosis also depends on the accelerated progression of atherosclerosis in the bypassed native artery segments [38]. The left main disease exemplifies the case in which documentation of hemodynamic significance of the lesion is particularly important and the FFR measurement is crucial.

In conclusion, there is a unified opinion regarding benefits of functional testing and FFR assessment before decisions on revascularization:

- visual assessment of lesions on coronary angiography is unreliable,

- lesions considered as hemodynamically significant on coronary angiography may not limit coronary blood flow,

- some of the intermediate lesions considered as hemodynamically insignificant cause reduction of the coronary reserve and should not be omitted when deciding about coronary intervention.

\section{The concept and significance of coronary flow reserve}

Coronary blood flow is determined by the myocardial oxygen demand [39]. The arterio-venous difference of blood oxygen saturation in coronary circulation is maximal. Therefore an increased oxygen demand caused by exercise may be met only by the increase of volumetric flow and not by the increase of oxygen uptake by myocardial cells as occurs in the case of skeletal muscles. Therefore an increase of coronary blood flow is the main response to increased myocardial oxygen demand $[40,41]$. Coronary circulation is able to transport several-fold higher blood volume during exercise or in the situation of pharmacologically provoked maximal vasodilatation of the resistance arteries (hyperemia) in comparison to the resting conditions. This property is called a coronary flow reserve. Cardiac output at rest is around $5.5 \mathrm{l}$, of which approximately $5 \%$ ( $255 \mathrm{ml} / \mathrm{min}, 0.8 \mathrm{ml} / \mathrm{min} / \mathrm{g}$ of the myocardium) is directed to the coronary arteries (around three fourths to the left and one fourth to the right). It is estimated that maximal exercise leads to a five- to six-fold increase of oxygen demand. Cardiac output and coronary flow increase adequately. An increase of volumetric flow causes vasodilatation of the resistance arterioles of the coronary circulation. This is a result of increased nitrate oxide release by the endothelium provoked by increased shear stress (so-called shear stress dependent dilation) [42]. Deficit of blood flow at rest appears only in case of critical stenosis, when auto-regulatory mechanisms are depleted. For that reason, blood flow through an up to $90 \%$ stenosis may be sufficient for the needs in resting conditions. If it is inadequate, regional contraction abnormalities known as hibernation of the myocardium appear.
Commonly used noninvasive methods of coronary reserve assessment are: electrocardiographic exercise test, stress echocardiography and SPECT. These methods, although sensitive in ischemia detection at the patient level, often do not permit one to determine the ischemia-related lesion [16, 17]. These studies are most frequently performed during qualification for invasive diagnostics. In situations when coronary angiography reveals changes in a patient who did not undergo functional assessment before or in the presence of multi-vessel coronary artery disease or serial stenoses within the same coronary artery, it is possible to use an invasive FFR measurements [16, 43].

To sum up, coronary reserve is the ability of the coronary circulation to transport a several-fold higher volume of blood during exercise, which is necessary to meet the increased oxygen demands of the myocardium. Although stress tests are characterized by good sensitivity and specificity in detection of ischemia, they often fail to identify an ischemia-related lesion. Many coronary interventions and surgical revascularizations are based on the visual assessment of the lesions. It may be assumed that if there was an effective noninvasive method for assessing functional significance of the particular lesions, many patients could avoid invasive coronary angiography and revascularization.

\section{Invasive measurement of fractional flow reserve}

Due to the fact that visual assessment of stenosis on coronary angiography is related to errors and does not express the functional significance of the lesion, decision making before revascularization depends more and more often on FFR assessment. The method is characterized by high repeatability and is particularly useful in assessment of borderline lesions, multi-vessel coronary artery disease, serial stenoses and left main stem disease [44]. The theoretical background for FFR assessment was formulated and introduced to clinical practice in the 1990s by Nico Pijls and Bernard de Bruyne. Despite the initial skepticism and resistance of invasive cardiologists, the method has gained widespread recognition and is currently used in many catheterization laboratories. The study provides information on the degree of reduction of coronary flow reserve by a particular lesion. In terms of principle, the value of FFR determines the maximal relation of flow through the stenosed coronary artery to maximal flow in the situation of an unstenosed artery [18]. In that sense FFR would be a parameter of relatively limited clinical utility as it is difficult to use it routinely. However, the idea of Pijls and de Bruyne goes further - it is known because of the physics of flow that a $Q$ flow in a part of the vessel is accompanied by a difference of pressures $\left(p_{\text {in }}-p_{\text {out }}\right)$ between the input (in) and output (out). The mutual relationship is always in the form of:

$$
\left(p_{\text {in }}-p_{\text {out }}\right)=R \cdot Q
$$


where the proportionality coefficient $R$ is the vascular resistance. In that case taking the signs from Figure 1, the fractional flow reserve may be described as:

$$
F F R=\frac{\left(p_{d}-p_{v}\right) / R}{\left(p_{a}-p_{v}\right) / R}
$$

where $p_{a}$ is the pressure in the aorta, $p_{v}$ is the central venous pressure and $p_{d}$ is the pressure below the stenosis. As $p_{v}$ is close to zero or at least significantly lower than $p_{d}$ and $p_{a}$ and the assessment is made at hyperemia, the FFR may be described as:

$$
F F R=\frac{p_{d}}{p_{a}} .
$$

Definitional scheme of fractional flow reserve related to the pressure is presented in Figure 1.

From the practical point of view, the test is based on simultaneous measurement of proximal to the stenosis (equivalent to mean aortic pressure) $\left(p_{a}\right)$ and distal to the stenosis $\left(p_{d}\right)$ under conditions of pharmacological hyperemia, which is equivalent to coronary blood flow at maximal exercise. Comercial guidewires used for that purpose (PressureWire (St. Jude Medical, Inc.) and PrimeWire (Volcano, Inc.)) have a tip with a piezoelectric sensor used to assess pressure distal the lesion. Hyperemia is most often provoked by an intravenous infusion of adenosine. Interestingly, the result of the FFR measurement is not influenced from hemodynamic conditions during the study such as the heart rate, variation in blood pressure or contractility $[45,46]$. Functional significance of the lesion depends on the degree of stenosis and on the size of the viable myocardium supplied by the vessel. Interpretation of the FFR should take into account collateral downstream flow [47] and the presence of myocardial scar $[19,48]$. In both of these situations the FFR is overestimated. When performing the FFR measurement in patients with multi-vessel coronary artery disease, one should keep in mind the influence of concomitant lesions. For example, in case of left main disease a tight stenosis in the proximal segment of the anterior descending artery or circumflex artery may underestimate the FFR measured within the left main stem [48]. Practical interpretation of the FFR is direct, and therefore FFR of 0.6 means that maximal volumetric flow through the stenosed artery at maximal exertion equals $60 \%$ of that observed in a situation without stenosis. The increase of FFR from 0.6 to 0.9 after coronary angioplasty means that the maximal flow increased by half in comparison to the situation before the intervention (improvement of the coronary flow reserve). The cut-off value for the FFR determined in the DEFER study was 0.75 . Results below 0.75 indicated a decrease of the coronary reserve. In most cases, if the FFR exceeds 0.8 there are no inducible ischemia. In the case of the "grey zone", which is FFR between 0.75 and 0.8 , a decision about revascularization should be based on the history of angina or results of stress testing [48-50]. To increase the sensitivity of FFR in

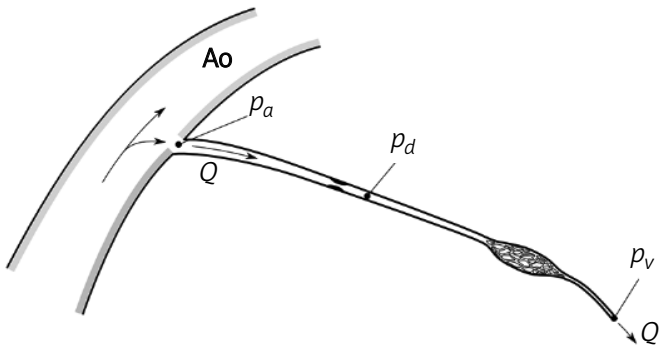

Fig. 1. Definitional scheme of fractional flow reserve related to the pressure

detection of lesions which are responsible for ischemia, an FFR cut-off value of 0.8 should be used [3]. The presence of angina in patients with normal FFR may be caused by the decrease of the coronary flow reserve due to reasons other than coronary artery disease. These include impairment of endothelium-dependent dilation of the arterioles ( $X$ syndrome), an increase of the microcirculation resistance in the course of small vessel disease or syndromes of high blood viscosity [51, 52]. In all of these situations a deficit of blood supply is caused by impaired transport of blood at levels other than epicardial arteries. In these situations it is helpful to assess the coronary flow reserve (CFR). A normal FFR and a low value of CFR indicate that the limitation of CFR is localized at the level of the resistance arteries or in the microcirculation [53]. The FFR measurement after coronary angioplasty with stenting is used to assess the efficacy of the procedure. The FFR $<0.9$ after the intervention indicates a suboptimal effect, which is related to the risk of adverse events in long-term observation, including restenosis $[13,54$, 55]. On the other hand, FFR $>0.9$ indicates a successful procedure and good long-term prognosis [56]. The main limitation of FFR measurement is its direct cost, which is comparable to IVUS. However, avoidance of unnecessary interventions lowers the total costs of treatment, which additionally justifies the use of this method not only for clinical, but also for economic reasons [5]. There are two sources of errors related to FFR measurement. They can result from the pathology of the coronary circulation or technical drawbacks of the procedure. The first group includes inability to achieve maximal hyperemia due to abnormal reactivity of resistance arteries and impaired flow in the microcirculation (diabetes, early phase of myocardial infarction). The second group consists of technical errors related to the procedure itself and includes the use of a guiding catheter with side holes, improper calibration of the system or flow disturbance caused by a catheter. In conclusion, FFR measurement is a reliable way to assess whether the lesion (borderline lesion in particular) is functionally significant to increase the objectivity of indications for revascularization. The test may be used in patients with stable and unstable coronary artery disease and for multi-vessel coronary artery disease, multi-level lesions, in-stent restenosis, left main stem disease or after myocardial infarction. According to European 
Society of Cardiology guidelines, FFR measurement is recommended for functional assessment of moderate lesions if there is no objective evidence of ischemia related to their presence (class of recommendation IA) [57]. The FFR measurement is an invasive study. Therefore, there is a search for reliable noninvasive methods of assessment of functional significance of the lesions in coronary arteries. One such solution is a computational calculation of FFR based on noninvasive tomographic imaging of the coronary arteries.

\section{Computational fluid dynamics}

Because measurement of FFR is based on the assessment of pressures, the idea of virtual FFR calculation was born in response to progress in computational methods of fluid dynamics. As such the CFD technique offers a potentially wide range of possibilities to obtain information on the variable parameters of flow, such as decrease of pressure across the stenosed artery under pre-defined conditions of increased volumetric flow. Increase of the pressure gradient through the hemodynamically significant lesion occurs during exercise or may be provoked pharmacolog ically (hyperemia). Significant changes of pressure gradient occur only if the lesion is functionally significant. Therefore CFD technique may be used for the assessment of hemodynamic significance of the lesions on angio-CT under predefined flow conditions.

The process of flow analysis by means of CFD is performed in three successive steps [58]:

- pre-processing, which consists of preparation of the model geometry and determination of the flow properties of the medium and the boundary conditions for the solution; - processing, which is the solution of the flow task for the defined conditions set at an earlier stage obtained by successive approximations until achievement of a permissible error;

- post-processing, which is the analysis and preparation of the results of the calculations.

Schematic presentation of the whole cycle of CFD analysis is presented in Figure 2.

Computational methods such as CFD have a generally good efficacy and adequacy. They have numerous applications and are slowly becoming a routinely used tool in the engineer's practice. Many specific applications could be mentioned, such as hydro- and aero-dynamics in mechanical engineering, pollutant dispersion, construction and urban planning. Translation and effective application of this methodology in fairly remote computing disciplines is easy, because it is bound by a universal mathematical model. It is common for all issues of fluid dynamics including those observed in coronary flow. The quality and adequacy of a particular practical application is determined by the choice of the geometric model of the flow area, rheology of the medium and adopted set of boundary conditions.

\section{Formulation and conditions of the simulation task}

A starting point for the development of the flow model to determine the $\mathrm{FFR}_{\mathrm{CT}}$ reserve factor must include a detailed geometric shape of the flow area. The most promising basis for its creation is an image of coronary arteries obtained by means of computed tomography. It is characterized by sufficient spatial resolution and atherosclerotic lesions are usually located in the proximal coronary artery segments. An angio-CT study has a very high negative predictive value, which means that it is a good method to exclude the presence of coronary artery disease $[59,60]$. Angio-CT as such is used to estimate the degree of stenosis, but does not give any information about the hemodynamic significance of detected lesions. A high percentage of tight stenoses described in tomography turn out to be nonsignificant on angiographic or FFR verification [59, 6163]. This is caused by limitations of the tomography, which overestimates the degree of stenosis of highly calcified plaques or in patients with high coronary calcium score (CCS) $[59,61]$. Assessment of distal plaques on angio-CT is also challenging. Another source of errors in tomographic assessment or exclusion of some vascular segments from the analysis includes artifacts generated by patient movement, arrhythmia, tachycardia or inadequate opacification of the arteries with the contrast medium $[63,64]$. Assessment of the degree of stenosis on coronary angiography alone may also be unreliable, which further impacts the correlation between the description of tomographic study and coronary angiography. A series of digital imaging and communications in medicine (DICOM) images obtained in angio-CT may be used for reconstruction of the shape of a particular artery or arteries in order to perform computational flow analysis. At the same time it is not necessary to modify the angioCT protocol and to expose a patient to additional doses of radiation or contrast agent [10,65-68]. The only condition necessary to calculate $\mathrm{FFR}_{\mathrm{CT}}$ based on computational methods is images of artery geometry and location of atherosclerotic plaques.

The process of computational analysis is multistep and includes:

- initial reconstruction of a 3D model of discrete peripheral surface by segmentation of DICOM images obtained with angio-CT;

- segmentation rarely provides a fully valuable model of discrete peripheral surface and therefore additional post-processing is needed;

- reconstruction of the central line of the peripheral surface serving to optimize the quality of the computational grid in the next step;

- representation of the discrete peripheral surface on the inside to obtain a final computational grid for the future CFD simulation;

- optionally, if appropriate, a computational grid may be further reconstructed to improve its quality. 


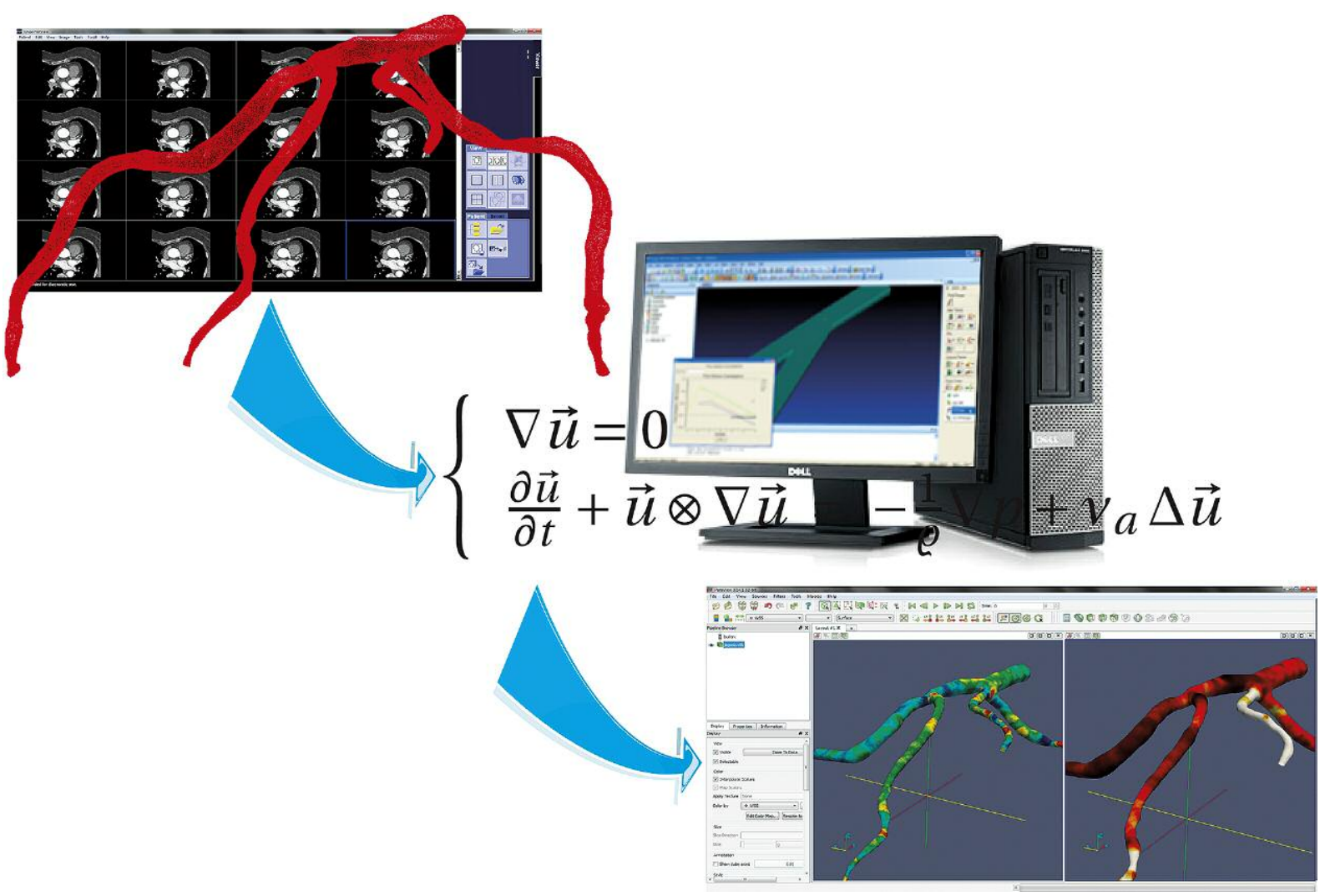

Fig. 2. Schematic realization of the computational flow problem by means of CFD

This is not the only possible strategy of computational grid construction, but it was successfully used in existing studies published by the authors $[58,69]$. A result of the central line reconstruction and a final computational grid constructed with the use of computed tomography images performed in the Computed Tomography Department of the Silesian Center for Heart Diseases are presented in Figure 3.

The resulting discrete model geometry must be supplemented by a model of the material itself, which is blood as a flowing medium. Although this is not an easy task, knowledge about the hematocrit may allow an effective empiric approximation of the interpersonal variables. It is far more difficult, but necessary, to complete the structure of a computational model of flow to introduce fully adequate boundary conditions of the inlet section of the artery. The easiest and most effective solution of this problem would be direct in vivo measurement, which is, however, in opposition to the idea of $F F R_{C T}$ itself. As part of the work undertaken by the authors a definition based on measurement taken from the literature has been proposed [70]. However, the world-leading team of HeartFlow Inc. [10, 65-68] tries to use an estimation based on the discrete parameters model with the following assumptions [71-73]:

- resting coronary flow is sufficient in relation to myocardial oxygen demand;
- it is proportional to the myocardial mass, which is calculated from the tomographic image;

- resting microcirculation resistance is inversely proportional to the vessel diameter, but this relationship is not linear.

This problem requires more detailed studies, as well as assessment of the impact and significance of many variables on the quality of $\mathrm{FFR}_{\mathrm{CT}}$ prediction. The recognition of this problem is important in terms of practical CFD applications in assessment of the hemodynamic importance of lesions in coronary angio-CT.

\section{Virtual assessment of fractional flow reserve}

For possible applications of the CFD technique in noninvasive assessment of the $\mathrm{FFR}_{\mathrm{CT}}$ it is important to note that to obtain computational solutions it is possible to use any of the commercially available packages. Besides, with a similar effect, it is possible to use any of the available open source packages. As mentioned earlier, specifics of these problems are not related to the mathematical model or the way it is solved or the type of data pre-processing and postprocessing. Because of the nonlinearity of the computational model and complex character of the flow, to achieve of the final solution requires a lot of computational power and time. The problem is even more important and serious as these calculations are supposed to be performed routinely (if we 


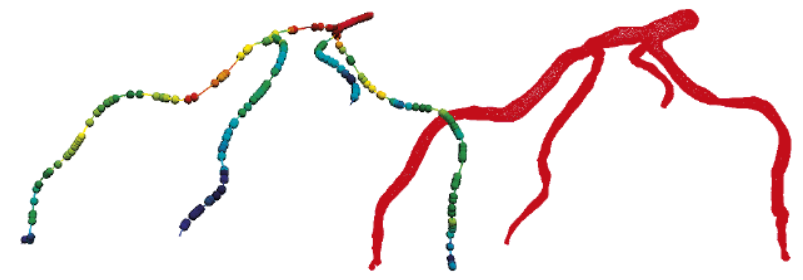

Fig. 3. Reconstruction of the central line and a final computational grid based on over 2 million finite elements

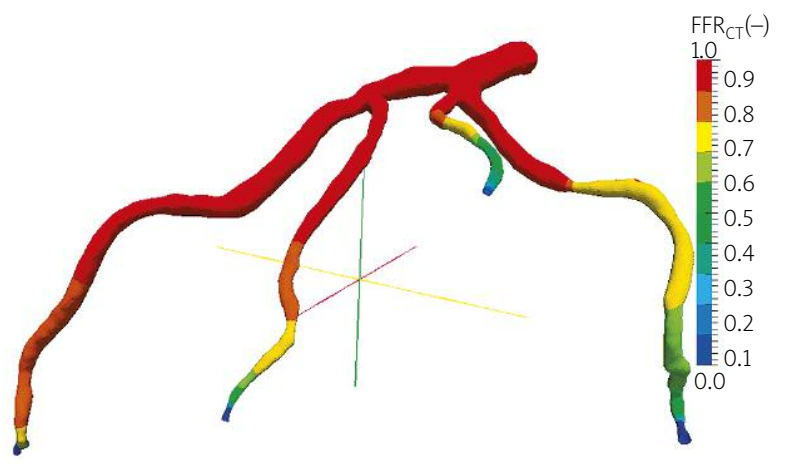

Fig. 4. $\mathrm{FFR}_{\mathrm{CT}}$ result based on coronary angio-CT images obtained by means of computational methods. For the circumflex artery the measured FFR ${ }_{C T}$ is lower than 0.8. It may be assumed that this stenosis is hemodynamically significant

think about introduction of postulated methods to diagnostics). Although the use of open source CFD software packages for simulation of coronary flow is convenient, the results obtained that way have very limited application in medical diagnostics. The main focus and purpose of these calculation tools are engineering applications and therefore none of them has the ability to calculate parameters such as FFR CT $_{\text {. }}$ It may be calculated only in the post-processing phase after independent analysis of results outside of the CFD package. For that reason every research team working on noninvasive $F_{F R}$ assessment uses dedicated self-made software. An example of our own results of FFR $\mathrm{CT}_{\mathrm{T}}$ based on the database of angio-CT studies performed in the Computed Tomography Department of the Silesian Center for Heart Diseases is presented in Figure 4.

\section{Diagnostic reliability of noninvasive fractional flow reserve evaluation}

The assessment of the quality of noninvasive coronary reserve measurement in the form of the FFR $\mathrm{CT}_{\mathrm{CT}}$ to identify hemodynamically significant lesions is an issue of great importance, although its practical implementation is difficult. One way to accomplish this is to directly compare the results to the FFR, which is obtained invasively. So far only one research team in the world has accomplished this task (HeartFlow Inc., http://heartflow.com) and published the results of the two clinical studies. The first study was published in 2011. These are the results of the DISCOVER-FLOW project (Diagnosis of Ischemia-Causing Stenoses Obtained Via Noninvasive Fractional Flow Reserve) [65]. The study included 103 patients with suspected or known coronary artery disease who underwent coronary angio-CT and coronary angiography and invasive FFR measurement. It is assumed that the reaction of microcirculation to adenosine is normal and leads to maximal hyperemia [74]. Inclusion criteria for the study consisted of: age $\geq 18$ years, the presence of $\geq 50 \%$ stenosis in a vessel of $\geq 2.0 \mathrm{~mm}$ and indications for coronary angiography with FFR measurement. The study looked at the correlation between the virtually calculated $\mathrm{FFR}_{\mathrm{CT}}$ and invasive measurement of the lesion significance (FFR) as a reference. The FFR $\mathrm{FT}_{\mathrm{T}}$ was calculated for 159 arteries with at least $50 \%$ stenosis. The FFR $\mathrm{R}_{\mathrm{CT}} \leq 0.80$ was considered significant. Per-vessel analysis of the quality of prediction demonstrated a good correlation between $\mathrm{FFR}_{\mathrm{CT}}$ and classic FFR $(R=0.717 ; p<0.0001$ in the Spearman test and $R=0.678$ and $p<0.0001$ in the Pearson test). Per-patient analysis revealed similarly good correlation coefficients and lack of systematic error. Calculation of the FFR $\mathrm{FT}_{\mathrm{CT}}$ permitted additional information to be obtained on hemodynamic significance of the lesions found on angio-CT and increased the discriminative ability of tomography through the reduction of false positive results (overestimation of the degree of stenosis). The method was also useful in relation to intermediate lesions (between 40\% and 69\%) [65-67]. The result of FFRCT depends on the quality of imaging of the arteries on computed tomography but, as demonstrated by the post hoc analysis of the DISCOVER-FLOW project, in the case of suboptimal studies or severe calcifications (CCS $>400$ ), the computational fractional flow reserve assessment was superior to visual assessment of the lesions [10]. It should be noted that only $1 / 4$ of the lesions reported as $60 \%$ to $69 \%$ on angio-CT in patients from the DISCOVERFLOW study remained functionally significant after FFR verification (which is FFR < 0.8) [65]. The DeFACTO study was a much broader project planned to assess the diagnostic

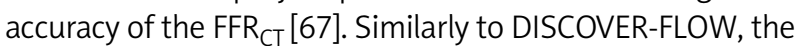
studied group consisted of patients with suspected or known coronary artery disease who underwent coronary angio-CT and coronary angiography with invasive FFR measurement. A comparative analysis was performed in 252 patients and significant stenosis assessed by means of the invasive FFR method was confirmed in 137 of them (54.4\%). A per-patient analysis showed diagnostic accuracy of $\mathrm{FFR}_{\mathrm{CT}}$ of $73 \%$ (95\% Cl: $67-78 \%)$, with sensitivity of $90 \%$ (95\% Cl: 84-95\%) and specificity of $54 \%$ (95\% Cl: $46-83 \%)$. Despite the fact that the diagnostic accuracy level did not meet the predefined primary end-point (the lower limit of one-sided 95\% confidence interval greater than 70\%) the diagnostic accuracy of angio-CT alone to detect lesions above $50 \%$ was low- 
er and reached 64\% (95\% Cl: 58-70\%), with sensitivity and specificity of respectively $84 \%$ (95\% Cl: $77-90 \%)$ and $42 \%$ (95\% Cl: 34-51\%). This means that $\mathrm{FFR}_{\mathrm{CT}}$ calculation improves diagnostic accuracy of tomography in comparison to visual assessment of coronary arteries on computed tomography. The advantage of $F F R_{C T}$ was particularly evident in the case of intermediate lesions. In that case, calculation of FFR $\mathrm{R}_{\mathrm{CT}}$ caused an over two-fold increase of the test sensitivity, from $37 \%$ to $82 \%$, without any influence on specificity. The negative predictive value of $\mathrm{FFR}_{\mathrm{CT}}$ was $84 \%(95 \% \mathrm{Cl}$ : $74-90 \%)$, which means that there is low probability that significant stenosis will not be detected by $\mathrm{FFR}_{\mathrm{CT}}$. In the absence of significant stenosis defined by means of $F F R_{C T}$ there is no need to perform coronary angiography, because the risk of the presence of a lesion requiring revascularization is low [67].

\section{Conclusions}

If the method of computational calculation of $F F R_{C T}$ is verified in clinical practice and the CFD calculation process is shortened, computed tomography of the coronary arteries supplemented by the per-vessel assessment of the stenosis significance will become a unique, noninvasive method able to determine with a probability which lesions require revascularization. The $\mathrm{FFR}_{C T}$ measurement will result in reduction of the percentage of patients unnecessarily referred for coronary angiography and will increase the percentage of patients in whom revascularization will lead to clinical benefits. The use of appropriate models of blood rheology and refined methods of artery segmentation, creation of computational grids and definitions of boundary conditions are expected to improve diagnostic accuracy of $F_{\text {FT }}$. Each of these three components must express interpersonal variability and properties. There is no easy solution of this problem, as it requires the work of interdisciplinary research teams. However, it creates new perspectives for improvement of accuracy of non-invasive diagnostic methods of atherosclerosis imaging in coronary arteries.

\section{References}

1. Lindstaedt M, Spiecker M, Perings C, et al. How good are experienced interventional cardiologists at predicting the functional significance of intermediate or equivocal left main coronary artery stenoses? Int J Cardiol 2007; 120: 254-261.

2. Botman KJ, Pijls NH, Bech JW, et al. Percutaneous coronary intervention or bypass surgery in multivessel disease? A tailored approach based on coronary pressure measurement. Catheter Cardiovasc Interv 2004; 63: 184-191.

3. Tonino PA, De Bruyne B, Pijls NH, et al. Fractional flow reserve versus angiography for guiding percutaneous coronary intervention. N Engl J Med 2009; 360: 213-224.

4. Lopez-Palop R, Pinar E, Lozano I, et al. Utility of the fractional flow reserve in the evaluation of angiographically moderate in-stent restenosis. Eur Heart J 2004; 25: 2040-2047.

5. Fearon WF, Bornschein B, Tonino PA, et al. Fractional Flow Reserve Versus Angiography for Multivessel Evaluation (FAME) Study Investigators. Economic evaluation of fractional flow reserve-guided per- cutaneous coronary intervention in patients with multivessel disease. Circulation 2010; 122: 2545-2550.

6. Yong AS, Ng AC, Brieger D, et al. Three-dimensional and two-dimensional quantitative coronary angiography, and their prediction of reduced fractional flow reserve. Eur Heart J 2011; 32: 345-353.

7. Fischer JJ, Samady H, McPherson JA, et al. Comparison between visual assessment and quantitative angiography versus fractional flow reserve for native coronary narrowings of moderate severity. Am J Cardiol 2002; 90: 210-215.

8. Tonino PA, Fearon WF, De Bruyne B, et al. Angiographic versus functional severity of coronary artery stenoses in the FAME study fractional flow reserve versus angiography in mul-tivessel evaluation. J Am Coll Cardiol 2010; 55: 2816-2821.

9. Shaw LJ, Berman DS, Maron DJ, et al. Optimal medical therapy with or without percutaneous coronary intervention to reduce ischemic burden: results from the Clinical Outcomes Utilizing Revascularization and Aggressive Drug Evaluation (COURAGE) trial nuclear ubstudy. Circulation 2008; 117: 1283-1291.

10. Min JK, Koo BK, Erglis A, et al. Effect of image quality on diagnostic accuracy of noninvasive fractional flow reserve: results from the prospective multicenter international DISCOVER-FLOW study. J Cardiovasc Comput Tomogr 2012; 6: 191-199.

11. Tron C, Kern MJ, Donohue TJ, et al. Comparison of quantitative angiographically derived and measured translesion pressure and flow velocity in coronary artery disease. Am J Cardiol 1995; 75: 111-117.

12. Iqbal MB, Shah N, Khan M, et al. Reduction in myocardial perfusion territory and its effect on the physiological severity of a coronary stenosis. Circ Cardiovasc Interv 2010; 3: 89-90.

13. Pijls NH, van Schaardenburgh P, Manoharan G, et al. Percutaneous coronary intervention of functionally nonsignificant stenosis: 5-year follow-up of the DEFER Study. J Am Coll Cardiol 2007; 49: 2105-2111.

14. Hachamovitch R, Hayes SW, Friedman JD, et al. Comparison of the short-term survival benefit associated with revascularization compared with medical therapy in patients with no prior coronary artery disease undergoing stress myocardial perfusion single photon emission computed tomography. Circulation 2003; 107: 29002907.

15. Stone GW, Maehara A, Lansky AJ, et al. A prospective natural-history study of coronary atherosclerosis. N Engl J Med 2011; 364: 226-235.

16. Melikian N, De Bondt $P$, Tonino $P$, et al. Fractional flow reserve and myocardial perfusion imaging in patients with angiographic multivessel coronary artery disease. JACC Cardiovasc Interv 2010; 3: 307314.

17. Ragosta M, Bishop AH, Lipson LC, et al. Comparison between angiography and fractional flow reserve versus single-photon emission computed tomographic myocardial perfusion imaging for determining lesion significance in patients with multivessel coronary disease. Am J Cardiol 2007; 99: 896-902.

18. Pijls NH, De Bruyne B, Peels K, et al. Measurement of fractional flow reserve to assess the functional severity of coronary-artery stenoses. N Engl J Med 1996; 334: 1703-1708.

19. De Bruyne B, Pijls NH, Bartunek J, et al. Fractional flow reserve in patients with prior myocardial infarction. Circulation 2001; 104: 157-162.

20. Pijls NH, Van Gelder B, Van der Voort P, et al. Fractional flow reserve. A useful index to evaluate the influence of an epicardial coronary stenosis on myocardial blood flow. Circulation 1995; 92: 3183-3193.

21. Sant'Anna FM, Silva EE, Batista LA, et al. Influence of routine assessment of fractional flow reserve on decision making during coronary interventions. Am J Cardiol 2007; 99: 504-508. 
22. Sels JW, Tonino PA, Siebert U, et al. Fractional flow reserve in unstable angina and non-ST-segment elevation myocardial infarction experience from the FAME (Fractional flow reserve versus Angiography for Multivessel Evaluation) study. JACC Cardiovasc Interv 2011; 4: 1183-1189.

23. Muller O, Mangiacapra F, Ntalianis A, et al. Long-term follow-up after fractional flow reserve-guided treatment strategy in patients with an isolated proximal left anterior descending coronary artery stenosis. JACC Cardiovasc Interv 2011; 4: 1175-1182.

24. Courtis J, Rodés-Cabau J, Larose E, et al. Usefulness of coronary fractional flow reserve measurements in guiding clinical decisions in intermediate or equivocal left main coronary stenoses. Am J Cardiol 2009; 103: 943-949.

25. Hamilos M, Muller O, Cuisset T, et al. Long-term clinical outcome after fractional flow reserve guided treatment in patients with angiographically equivocal left main coronary artery stenosis. Circulation 2009; 120: 1505-1512.

26. Bech GJ, Droste H, Pijls NH, et al. Clinical outcome in patients with intermediate or equivocal left main coronary artery disease after deferral of surgical revascularization on the basis of fractional flow reserve measurements. Am Heart J 2006; 152: 156e1-156e9.

27. Lindstaedt $M$, Yazar $A$, Germing $A$, et al. Clinical outcome in patients with intermediate or equivocal left main coronary artery disease after deferral of surgical revascularization on the basis of fractional flow reserve measurements. Am Heart J 2006; 152: 156.e1-156.e9.

28. De Bruyne B, Pijls NH, Kalesan B, et al. Fractional flow reserve-guided $\mathrm{PCl}$ versus medical therapy in stable coronary disease. N Engl J Med 2012; 367: 991-1001.

29. Boden WE, O'Rourke RA, Teo KK, et al. Optimal medical therapy with or without PCI for stable coronary disease. N Engl J Med 2007; 356: 1503-1516.

30. Frye RL, August P, Brooks MM, et al. A randomized trial of therapies for type 2 diabetes and coronary artery disease. N Engl J Med 2009; 360: 2503-2515.

31. Goden WE. Mounting evidence for lack of PCI benefit in stable ischemic heart disease: what more will it take to turn the tide of treatment? Comment on "initial coronary stent implantation with medical therapy vs medical therapy alone for stable coronary artery disease". Arch Intern Med 2012; 172: 319-321.

32. Velazquez EJ, Lee KL, Deja MA, et al. Coronary-artery bypass surgery in patients with left ventricular dysfunction. N Engl J Med 2011; 364: 1607-1616.

33. Legutko J, Dudek D, Rzeszutko L, et al. Fractional flow reserve assessment to determine the indications for myocardial revascularisation in patients with borderline stenosis of the left main coronary artery. Kardiol Pol 2005; 63: 499-506.

34. Botman CJ, Schonberger J, Koolen S, et al. Does stenosis severity of native vessels influence bypass graft patency? A prospective fractional flow reserve-guided study. Ann Thorac Surg 2007; 83: 2093-2097.

35. Berger A, MacCarthy PA, Siebert $U$, et al. Long-term patency of internal mammary artery bypass grafts relationship with preoperative severity of the native coronary artery stenosis. Circulation 2004 110 (suppl. II): II-36-II-40.

36. Shimizu T, Hirayama $\mathrm{T}$, Suesada $\mathrm{H}$, et al. Effect of flow competition on internal thoracic artery graft: postoperative velocimetric and angiographic study. J Thorac Cardiovasc Surg 2000; 120: 459-465.

37. Wasilewski J, Kiljański T, Głowacki J, et al. Significance of disturbed flow in coronary artery grafts patency. Kardiochir Torakochir Pol 2011; 8: 117-120.

38. Wasilewski J, Peryt-Stawiarska S, Przybylski R, et al. Should we pay attention to the place where the coronary artery bypass is grafted to the left anterior descending artery? Kardiochir Torakochir Pol 2012; 9: 182-185.

39. Colin P, Ghaleh B, Monnet X, et al. Effect of graded heart rate reduction with ivabradine on myocardial oxygen consumption and diastolic time in exercising dogs. Pharmacol Exp Ther 2004; 308: 236-240.

40. Duncker DJ, Merkus D. Regulation of coronary blood flow. Effect of coronary artery stenosis. Arch Mal Coeur Vaiss 2004; 97: 1244-1250.

41. Duncker DJ, Bache RJ. Regulation of coronary blood flow during exercise. Physiol Rev 2008; 88: 1009-1086.

42. Lamontagne D, Pohl U, Busse R. Mechanical deformation of vessel wall and shear stress determine the basal release of endothelium-derived relaxing factor in the intact rabbit coronary vascular bed. Circ Res 1992; 70: 123-130.

43. Topol EJ, Ellis SG, Cosgrove DM, et al. Analysis of coronary angioplasty practice in the United States with an insurance-claims data base. Circulation 1993; 87: 1489-1497.

44. de Bruyne B, Bartunek J, Sys SU, et al. Simultaneous coronary pressure and flow velocity measurements in humans. Feasibility, reproducibility, and hemodynamic dependence of coronary flow velocity reserve, hyperemic flow versus pressure slope index, and fractional flow reserve. Circulation 1996; 94: 1842-1849.

45. Kolli KK, Banerjee RK, Peelukhana SV, et al. Influence of heart rate on fractional flow reserve, pressure drop coefficient, and lesion flow coefficient for epicardial coronary stenosis in a porcine model. Am J Physiol Heart Circ Physiol 2011; 300: H382-H387.45

46. Pijls NH, Bech GJ, De Bruyne B, et al. Clinical assessment of functional stenosis severity: use of coronary pressure measurements for the decision to bypass a lesion. Ann Thorac Surg 1997; 63 (6 Suppl): S6-11.

47. Peelukhana SV, Back LH, Banerjee RK. Influence of coronary collateral flow on coronary diagnostic parameters: an in vitro study. J Biomech 2009; 42: 2753-2759.

48. Pijls NH, Sels JW. Functional measurement of coronary stenosis. J Am Coll Cardiol 2012; 59: 1045-1057.

49. Courtis J, Rodés-Cabau J, Larose E, et al. Comparison of medical treatment and coronary revascularization in patients with moderate coronary lesions and borderline fractional flow reserve measurements. Catheter Cardiovasc Interv 2008; 71: 541-548.

50. Pijls NH, Kern MJ, Yock PG, et al. Practice and potential pitfalls of coronary pressure measurement. Catheter Cardiovasc Interv 2000; 49: 1-16.

51. Lee BK, Durairaj A, Mehra A, et al. Microcirculatory dysfunction in cardiac syndrome $X$ : role of abnormal blood rheology. Microcirculation 2008; 15: 451-459.

52. Lanza GA. Cardiac syndrome X: a critical overview and future perspectives. Heart 2007; 93: 159-166

53. Pijls NH, De Bruyne B, Smith L, et al. Coronary thermodilution to assess flow reserve: validation in humans. Circulation 2002; 105 : 2482-2486

54. Klauss V, Erdin P, Rieber J, et al. Fractional flow reserve for the prediction of cardiac events after coronary stent implantation: results of a multivariate analysis. Heart 2005; 91: 203-206.

55. Nam CW, Hur SH, Cho YK, et al. Relation of fractional flow reserve after drug-eluting stent implantation to one-year outcomes. Am J Cardiol 2011; 107: 1763-1767.

56. Pijls NH, Klauss V, Siebert U, et al. Fractional Flow Reserve (FFR) Post-Stent Registry Investigators. Coronary pressure measurement after stenting predicts adverse events at follow-up: a multicenter registry. Circulation 2002; 105: 2950-2954.

57. Task Force on Myocardial Revascularization of the European Society of Cardiology (ESC) and the European Association for Cardio- 
Thoracic Surgery (EACTS); European Association for Percutaneous Cardiovascular Interventions (EAPCI), Wijns W, Kolh P, Danchin N, et al. Guidelines on myocardial revascularization. Eur Heart J 2010; 31: 2501-2555.

58. Wasilewski J, Mirota K, Peryt-Stawiarska S, et al. An introduction to computational fluid dynamics based on numerical simulation of pulsatile flow in the left coronary artery. Kardiochir Torakochir Pol 2012; 9: 366-374.

59. Budoff MJ, Dowe D, Jollis JG, et al. Diagnostic performance of 64multidetector row coronary computed tomographic angiography for evaluation of coronary artery stenosis in individuals without known coronary artery disease: results from the prospective multicenter ACCURACY (Assessment by Coronary Computed Tomographic Angiography of Individuals Undergoing Invasive Coronary Angiography) trial. J Am Coll Cardiol 2008; 52: 1724-1732.

60. Meijboom WB, Meijs MF, Schuijf JD, et al. Diagnostic accuracy of 64-slice computed tomography coronary angiography: a prospective, multicenter, multivendor study. J Am Coll Cardiol 2008; 52: 2135-2144.

61. Meijboom WB, Van Mieghem CA, van Pelt N, et al. Comprehensive assessment of coronary artery stenoses: computed tomography coronary angiography versus conventional coronary angiography and correlation with fractional flow reserve in patients with stable angina. J Am Coll Cardiol 2008; 52: 636-643.

62. Gaemperli O, Schepis T, Koepfli P, et al. Accuracy of 64-slice CT angiography for the detection of functionally relevant coronary stenoses as assessed with myocardial perfusion SPECT. Eur J Nucl Med Mol Imaging 2007; 34: 1162-1171.

63. Gaemperli O, Schepis T, Valenta I, et al. Functionally relevant coronary artery disease: comparison of 64-section CT angiography with myocardial perfusion SPECT. Radiology 2008; 248: 414-423.

64. Hamon M, Biondi-Zoccai GG, Malagutti $P$, et al. Diagnostic performance of multislice spiral computed tomography of coronary arteries as compared with conventional invasive coronary angiography: a meta-analysis. J Am Coll Cardiol 2006; 48: 1896-1910.

65. Koo BK, Erglis A, Doh JH, et al. Diagnosis of ischemia-causing coronary stenoses by noninvasive fractional flow reserve computed from coronary computed tomographic angiograms. Results from the prospective multicenter DISCOVER-FLOW (Diagnosis of Ischemia-Causing Stenoses Obtained Via Noninvasive Fractional Flow Reserve) study. J Am Coll Cardiol 2011; 58: 1989-1997.

66. Min JK, Koo BK, Erglis A, et al. Usefulness of noninvasive fractional flow reserve computed from coronary computed tomographic angiograms for intermediate stenoses confirmed by quantitative coronary angiography. Am J Cardiol 2012; 110: 971-976.

67. Min JK, Leipsic J, Pencina MJ, et al. Diagnostic accuracy of fractional flow reserve from anatomic CT angiography. JAMA 2012; 26: 1237 1245.

68. Min JK, Berman DS, Budoff MJ, et al. Rationale and design of the DeFACTO (Determination of Fractional Flow Reserve by Anatomic Computed Tomographic AngiOgraphy) study. J Cardiovasc Comput Tomogr 2011; 5: 301-309.

69. Wasilewski J, Mirota K, Peryt-Stawiarska S, et al. Numerical simulation of pulsatile blood flow in the left coronary artery in the context of atherosclerotic plaques distribution and structure. In: Mechanic in medicine. Korzyński M, Cwanek Lubimov VJ (eds.). Publishing of Rzeszow University of Technology, Rzeszow 2008.

70. Perktold K, Nerem RM, Peter RO. A numerical calculation of flow in a curved tube model of the left main coronary artery. J Biomech 1991; 24: 175-189.
71. Kamiya A, Togawa T. Adaptive regulation of wall shear stress to flow change in the canine carotid artery. Am J Physiol 1980; 239: $\mathrm{H} 14-\mathrm{H} 21$.

72. Takx RA, Moscariello A, Schoepf UJ, et al. Quantification of left and right ventricular function and myocardial mass: comparison of lowradiation dose 2 nd generation dual-source CT and cardiac MRI. Eur J Radiol 2012; 81: e598-e604.

73. Zarins CK, Zatina MA, Giddens DP, et al. Shear stress regulation of artery lumen diameter in experimental atherogenesis. J Vasc Surg 1987; 5: 413-420.

74. Wilson RF, Wyche K, Christensen BV, et al. Effects of adenosine on human coronary arterial circulation. Circulation 1990; 82: 1595-1606. 